\title{
Comparison of Blood Lipid and Lipoprotein Amount of Wrestlers and Skiers
}

\author{
Feyzullah Koca \\ Correspondence: Feyzullah KOCA, Faculty of Sport Sciences, Erciyes University, Kayseri, Turkey
}

Received: April 4, 2019 Accepted: May 10, $2019 \quad$ Online Published: May 15, 2019

doi:10.11114/jets.v7i7.4250 URL: https://doi.org/10.11114/jets.v7i7.4250

\begin{abstract}
In this study it is aimed to compare form blood parameters lipid and lipoprotein values of wrestlers and skiers who have different training levels. In addition, was to examine the risks of cardiovascular diseases for wrestler and skiers. In order to achieve this purpose, 33 male of elite wrestling and ski athletes measured in the study. In this study, Triglyceride (TG), were determined Total Cholesterol (TC), HDL-C and LDL-C levels (With Hitachi 717 autoanalyser). To determine the differences between groups "independent $\mathrm{t}$ " tests were performed.

In this study, there were significant differences in plasma LDL-C, HDL-C, and TC values between wrestlers and skiers $(p<.05$ and $p<0,001)$. There were no significant differences in plasma TG values between wrestlers and skiers $(p>.05)$. In this study, HLC values of skiers were found to be significantly higher than wrestlers $(\mathrm{p}<0.001)$. In this study the cardiovascular risk ratios (TC/HDL-C) were found to be $3.39 \mathrm{mg} / 100 \mathrm{cc}$ for wrestlers and $2.80 \mathrm{mg} / 100 \mathrm{cc}$ for skiers. Ratios LDL-C/HDL-C were found $1.76 \mathrm{mg} / 100 \mathrm{cc}$ for wrestlers and $1.45 \mathrm{mg} / 100 \mathrm{cc}$ for skiers.

Conclusion: Although the wrestlers' training levels were always found to be difference than the skiers, TG values were not found to be different. But the HDL-C, LDL-C, and TC levels of skiers were found better than wrestlers. This results shows that medium and high level of different exercises did cause little differences in blood plasma lipid and lipoprotein levels. Plasma Lipid and lipoprotein values of the wrestler and skiers was accept good. Wrestling and ski athletes would not be exposed to risk of cardiovascular diseases. Blood parameter values should be examined separately on Cross-country skiers and alpine skiers.
\end{abstract}

Keywords: wrestler, skier and blood parameters

\section{Introduction}

There is important, stable and strong evidence that physical activity was a deterrent for developing many forms of cardiovascular disease. Regular physical activity is thought to reduce cardiovascular disease risk, at least in part, by its positive influence on circulating plasma lipids and lipoproteins (Durstine et al., 2001). Positive effects of applied long time regular exercises on physical, physiological, psychological and motoric features have been reported. At one of the most important is positive effects of regular exercise is on blood biochemistry. Regular and good-tuned intensity aerobic exercises reduces blood lipid levels, total cholesterol, LDL cholesterol, triglycerides, while increases HDL cholesterol levels (Koç, 2011). Cross-sectional studies support a significant positive change effect of exercise on plasma lipids and lipoproteins in male (Durstine et al., 2001). Many data provide stronger evidence for lower TG (Total Triglyceride) and higher HDL-C levels in physically active persons (Fritz, 1987). By Lippi et al,(2006) in a search, it found total cholesterol (TC), high-density lipoprotein cholesterol (HDL-C), triglycerides (TG), low-density lipoprotein cholesterol (LDL-C) ratio and the atherogenic index of plasma were significantly lower in both categories of professional athletes, whereas the mean HDL-C concentration was significantly higher. Both aerobic and anaerobic exercise can raise high-density lipoprotein cholesterol levels (HDL-C), decrease total cholesterol (TC), and lower the TC/HDL-C ratio (Tran et al., 1983; Thompson et al, 1991).

Many studies have shown that exercise can cause improving effect on plasma serum TG, HDL-C, and LDL-C (Gullu et al., 2013). Aerobic exercise training has been associated with positive effects on lipid profiles in the general population, most notably in TG and HDL levels (Earnest et al., 2013; Mann et al., 2014; Ruppar et al.,2014). The results of studies involving exercise interventions of moderate to high intensity three to five times per week for $>3$ months indicated a decreases in TG and LDL-C concentrations, general increase in HDL-C, and no change in total cholesterol (Pedersen and Saltin,2006). Kraus et al (2002) noted a significant improvement in lipoprotein profiles of subjects who exercised 
regularly over a period of 6 months. They were found increased HDL-C and decreased very-low-density lipoproteins and TGs. Sarzynski et al (2015) found regular exercise imparts several beneficial effects on lipid particle subclasses, including significant increases. It was found in high HDL-C particles and significant decreases in medium HDL particles. A large number of studies indicate an association between regular physical activities with a variety of health effects. While the credibility of data on this relationship varies from case to case. It is clear that physical inactivity is a major cause of premature mortality and morbidity from chronic diseases (Taylor et al., 2004; WHO, 2004). There is substantial, consistent and strong evidence that physical activity is a deterrent for developing many forms of cardiovascular disease (Imamoğlu et al, 2005; Çetinkaya and İmamoğlu,2018). Many study show that the high cholesterol is related with coronary heart disease (CHD). LDL-C/HDL-C values can show arteriosclerosis disease risk. Blood lipids and lipoprotein profiles of physically active groups reflect a reduced risk for the development of cardiovascular according their inactive counterparts (Fletcher et al., 1992, Durstine et al., 2001; Stambler et al, 1986). Cardiovascular diseases for people are the leading causes of deaths worldwide (Cutler, 2006). Plasma low blood levels of high-density lipoprotein cholesterol (HDL-C) are an independent risk factor for cardiovascular diseases (Franceschini, 2001; Boden, 2000). It has been accept that exercises have a positive effect on lipid and lipoprotein metabolism (Bedir et al., 1998). The plasma lipid and lipoprotein abnormalities play a major role in the development and progression of coronary artery disease. Abnormal blood parameters is participate negative in many physiological and biochemical events in human body (İmamoğlu et al., 2017). In this study it is aimed to compare form blood parameters lipid and lipoprotein values of wrestlers and skiers who have different training levels. In addition, was to examine the risks of cardiovascular diseases for wrestler and skiers.

\section{Material and Methods}

Subjects: The study included 33 participants, both groups, age 17-26 years. 16 male wrestlers who do sports for 12.78 years ( high intensity exercise), 17 male skiers who do sports at least 12.09 years (high intensity exercise), total 33 subjects participated in this study. The groups are the elite senior athletes. Athletes in the study was at least five years of elite athletes. All subjects were healthy. All athletes was measured their height and weight with anthropometry and medical scales reach tagged according to standard procedure.

Lipid and Lipoprotein Measurement: Plasma lipids was taken from a blood sample provide by puncture of the cubital vein, the concentrations of lipids. A blood sample was taken in the morning. After 12 hours of abstinence is not from food. Fasting blood samples were taken in the morning. Plasma TG, TC, HDL-C, LDL-C levels were analyses (with Hitachi 717 Autoanalyser). Total cholesterol (TC), triglycerides (TG), HDL and LDL were determined using classical methods.

$$
\text { Body Mass Index }(\text { BMI })=\text { Body Weight }(\mathrm{kg}) / \text { Height }(\mathrm{m})^{2}=\mathrm{kg} / \mathrm{m}^{2}
$$

Analysis of Data: Analysis was performed on SPSS 22 version. Kolmogorov-Smirnov test was used to evaluate the normality of parameters. To determine the differences between groups "independent $t$ " tests were performed.

\section{Results}

In Table 1, were given physical anthropometric and motoric characteristics. In Table 2, were given comparison of serum lipid values between wrestling and ski athletes. In Table 3, were showed cardiovascular risk status of wrestling and ski athletes.

Table 1. Physical Characteristics of Wrestlers and Skiers

\begin{tabular}{|c|c|c|c|c|c|}
\hline Parameters & Categories & $\mathrm{N}$ & Mean & Std. Deviation & $\mathrm{t}$ \\
\hline \multirow[t]{2}{*}{ Age (year) } & Wrestlers & 16 & 22,06 & 1,88 & \multirow[t]{2}{*}{0,19} \\
\hline & Skiers & 17 & 21,94 & 1,68 & \\
\hline \multirow[t]{2}{*}{ Age of training (year) } & Wrestlers & 16 & 12,78 & 2.4 & \multirow[t]{2}{*}{0,45} \\
\hline & Skiers & 17 & 12,09 & 3.5 & \\
\hline \multirow[t]{2}{*}{ Height $(\mathrm{cm})$} & Wrestlers & 16 & 170,94 & 4,40 & \multirow[t]{2}{*}{$-2,76^{*}$} \\
\hline & Skiers & 17 & 175,47 & 4,99 & \\
\hline \multirow[t]{2}{*}{ Body Weight (kg) } & Wrestlers & 16 & 75,44 & 10,90 & \multirow[t]{2}{*}{$2,25 *$} \\
\hline & Skiers & 17 & 68,76 & 5,41 & \\
\hline \multirow[t]{2}{*}{ BMI $\left(\mathrm{kg} / \mathrm{m}^{2}\right)$} & Wrestlers & 16 & 25,87 & 4,02 & \multirow[t]{2}{*}{$3,23 *$} \\
\hline & Skiers & 17 & 22,36 & 1,90 & \\
\hline
\end{tabular}


Table 2. Comparison of Serum Lipid Values of Wrestling and Skiers Groups

\begin{tabular}{|c|c|c|c|c|c|}
\hline $\mathrm{Mg} / 100 \mathrm{cc}$ & Groups & n & Mean & Std. Deviation & $\mathrm{t}$ \\
\hline \multirow{2}{*}{$\mathrm{TC}$} & Wrestlers & 16 & 181,25 & 6,60 & \multirow{2}{*}{$3,27 *$} \\
\hline & Skiers & 17 & 172,41 & 8,71 & \\
\hline \multirow{2}{*}{ TG } & Wrestlers & 16 & 94,25 & 7,89 & \multirow{2}{*}{1,58} \\
\hline & Skiers & 17 & 89,29 & 9,87 & \\
\hline \multirow[b]{2}{*}{ HDL-C } & Wrestlers & 16 & 53,50 & 1,79 & \multirow{2}{*}{$-10,85^{* *}$} \\
\hline & Skiers & 17 & 61,65 & 2,45 & \\
\hline \multirow[b]{2}{*}{ LDL-C } & Wrestlers & 16 & 120,13 & 7,03 & \multirow{2}{*}{$5,65^{* *}$} \\
\hline & Skiers & 17 & 108,88 & 4,09 & \\
\hline
\end{tabular}

Table 3. Risk of Cardiovascular Disease of Wrestlers and Skiers

\begin{tabular}{|c|c|c|c|c|c|}
\hline $\mathrm{Mg} / 100 \mathrm{cc}$ & Groups & $\mathrm{N}$ & Mean & Std. Deviation & $\mathrm{t}$ \\
\hline \multirow[b]{2}{*}{ TC/HDL-C } & Wrestlers & 16 & 3,39 & , 17 & \multirow[b]{2}{*}{$9,79 * *$} \\
\hline & Skiers & 17 & 2,80 &, 17 & \\
\hline \multirow[b]{2}{*}{ LDL-C/HDL-C } & Wrestlers & 16 & 1,76 & 15 & \multirow[b]{2}{*}{$5,16^{* * *}$} \\
\hline & Skiers & 17 & 1,45 &, 18 & \\
\hline
\end{tabular}

\section{Discussion}

In this study, wrestlers has found 22.06 years old and skiers were 21.94 years old. Training ages were 12.78 years in wrestlers and 12.09 years in skiers. There was no significant difference between the ages of skiers and wrestlers and the age of training ( $>>0.05$ ). The Height of the wrestlers was found to be $170.94 \mathrm{~cm}$ and in the skier's $175.47 \mathrm{~cm}$. Body weights were $75.44 \mathrm{~kg}$ in wrestlers and $68.76 \mathrm{~kg}$ in skiers. Body mass indexes were $25.87 \mathrm{~kg} / \mathrm{m}^{2}$ in wrestlers and 22.36 $\mathrm{kg} / \mathrm{m}^{2}$ in skiers. The difference between height, body weight and BMI values of wrestlers and skiers were statistically significant $(\mathrm{p}<0.05)$. Skiers were taller height and have less body weight than wrestlers. Wrestlers' BMI value was higher than skiers. Elevation in body mass index (BMI) has been associated with less favorable lipoprotein profiles (811). Elevation in the BMI has also been associated with an increased relative risk of CHD, as well as an increased mortality due to cardiovascular disease (CVD), (Manson et al., 1987; Stevens et al., 1998; Garrison et al., 1996; Tunstall et al., 1997; Kujala et al., 1994). Previous epidemiologic studies have demonstrated an increased risk of CHD and cardiovascular death with an increase in BMI (Garry and McShane, 2001). According to this study, the health risk of the wrestlers is higher than the skiers.

When literature was reviewed about effects of exercise on plasma lipids, lipoproteins, results indicated that moderate and low intensity exercises are of great importance. These events show increase of HDL-C, Decrease of LDL-C and increase protective effects to arteriosclerosis (Imamoğlu et al., 1998). Most studies indicate smaller, non-significant differences in TC and LDL-C levels between regular exercise-trained and sedentary persons (Wood, 1996). Koç (2011) in a study, found significant reductions in the exercise-induced triglyceride, cholesterol, and LDL cholesterol. In a study, it was reported that the exercise has no effect on triglyceride and cholesterol parameters, but caused an increase in HDL cholesterol level and reduction in LDL cholesterol level (Leon and Sanches, 2001). In a study, İmamoğlu et al. (2005) stated that there found no significant differences in plasma TC and TG values between the groups of wrestlers and students. No significant differences were found in HDL-C and LDL-C values between wrestlers and male students with training. In this study TG levels were not found to be different between wrestlers and skiers. The Triglyceride concentration did not differ significantly between the wrestlers and skiers. In this study, there found significant differences in plasma Total Cholesterol, LDL-C, and HDL-C values between wrestlers and skiers ( $\mathrm{p}<.05$ and $\mathrm{p}<0,001)$.There were no significant differences in plasma TG values between wrestlers and skiers ( $\mathrm{p}>.05)$. TC and LDL-C values of wrestlers were significantly high when compared with the same values of skiers. Skiers' HDL-C level was higher than wrestlers. 
A lot of studies support that aerobic exercises increase the HDL-C levels. In other words, it is emphasized that aerobic exercise is important for the athletes who attend to the strength training, too (Higuchi et al., 1989). Koç (2011) in a study, found significant increase with exercise in HDL levels. In a study; although the group A wrestlers' training levels were always higher than group B Wrestlers, the TG and HDL-C values were not found to be different. But the HDL-C levels of group A wrestlers were found to be better than group B Wrestlers (Aydoğan, 2017). This situation was stated to be the result of intensive education and nutrition. Majority of the studies showed that decreased triglycerides, cholesterol and LDL cholesterol levels, and increased HDL was the result of applied training when severity of exercise, duration and frequency were approved. Skiers and wrestlers have different training conditions and nutrition. Even in skiing, there are differences in training conditions, energy systems and anthropometric properties (Güneş et al., 2019). In a study by Eryilmaz and Polat (2018), alpine skiers found that their aerobic capacity was lower compared to cross-country skiers. Considering that cross-country skiing competitions take place between 10 and 120 minutes, the aerobic capacity of cross-country skiers is expected to be high (Staib et al., 2000). Therefore Cross-country skiers use endurance training to improve their aerobic capacity in their training programs (Holmberg, 2015; Sandbakk and Holmberg, 2014; Seiler and Kjerland, 2006). On the other hand, considering the expectation of sportive performance in the alpine skiing, which varies between 45 seconds and 3 minutes, the anaerobic power values of the alpine skiers should be high (White and Johnson, 1991). For this reason, alpine skiers apply training programs that mainly include anaerobic exercises such as speeding exercises, resistance exercises, shifting resistances, and plyometric exercises (Bosco et al., 1994; Hydren et al., 2013). Wrestlers compete in a challenging environment involving repetitive bouts of high-intensity actions (e.g., attacks and counterattacks) alternated by submaximal work of low-intensity activity or pause. Wrestler's physiological demands are complex, requiring athletes to have highly developed capacities of maximal strength, power, muscular endurance, maximal aerobic power, and anaerobic capabilities. The short quick bursts of maximal power activities during the match are maintained by the anaerobic system. The aerobic system manages the wrestler's ability to maintain effort throughout the duration of the encounter and accelerates the recovery process within and between successive matches (Callan et al., 2000; Karnincic,et al.,2009; Chaabene et al.,2017). In this study, HLC values of skiers were found to be significantly higher than wrestlers. When it comes to levels of HDL-C showed statistically significant differences between wrestlers and skiers. Because male wrestlers perform mostly nonaerobic exercises and strength training, the exercises like these did not increase the HDL-C levels.

Regular and appropriate exercises of elite athletes are to better to level their lipid profiles (Ginsburg et al., 1996; Dressendorfer and Gahagen, 1979). In a study by Aydogan (2017) on wrestler's shows that medium and high level of exercises did cause little differences in plasma lipid and lipoprotein values. lippi et al (2006) in a study, found lower TC/HDL-C ratio in professional skiers and lower TC/HDL-C ratio and TC in professional cyclists were significantly associated with increased aerobic physical activity. The people who have HDL-C cholesterol levels under $40 \mathrm{mg} / 100 \mathrm{cc}$ have more than three times of risk of cardiovascular diseases than people who have high HDL-C levels (Wood,1986). The periodic risk of heart disease can estimate by dividing TC to HDL-C. As a result of the estimation 4.5-5 levels show important cardiovascular disease risk, 3.8-4 levels show low cardiovascular disease risk (Rosato and Frank, 1990; Werner at al., 1990). In another value, the risk factor is high if TC/HDL-C ratio is higher than 5. The risk factor is low if the ratio is lower than 3.5 (Edward et al, 1992). İmamoğlu et al (2005) in a study, mentioned that lipid and lipoprotein values of the groups have reported good. It was accept that the individuals in these groups would not be exposed to risk of cardiovascular diseases. In this study the cardiovascular risk ratios (TC/HDL-C) were found to be $3.39 \mathrm{mg} / 100 \mathrm{cc}$ for wrestlers and $2.80 \mathrm{mg} / 100 \mathrm{cc}$ for skiers. Ratios LDL-C/HDL-C were found $1.76 \mathrm{mg} / 100 \mathrm{cc}$ for wrestlers and 1.45 $\mathrm{mg} / 100 \mathrm{cc}$ for skiers. The cardiovascular risk ratio of wrestlers are higher than skiers. High-intensity aerobic training results in improvement in high-density lipoprotein cholesterol (Tambalis et al.,2008). But the wrestlers' training form were mostly anaerobic. Some skiers' training program (for Cross-country skiers) are more aerobic than wrestlers, reducing the risk of heart disease. It is showe that cardiovascular risk factors are greatly decreased through the cardiovascular changes that occur with regular and long-term exercise (Çicek et al., 2017). Physical activity, exercise and sport has proved their multiple positive effects on health. Regular physical exercise interaction induces changes in lipoprotein metabolism. Therefore thus reduces the cardiovascular risk (Labovic et al., 2015). Many studies suggest that individually measured and programmed physical activity, and the implementation of primarily aerobic physical activity, leading to increased concentrations of HDL cholesterol. Also lowering the value triglyceride, total and LDL cholesterol (Lilic et al., 2009). When the intensity of the workout well controlled, the energy consumption is a major factor affecting lipids and lipoproteins (Lohman et al.,1991).Therefore, Wrestlers should add low-intensity and long-term running's to their training.

Skiers need moderate and high aerobic capacity and very high anaerobic power. Besides aerobic and anaerobic power; motor parameters such as quickness, balance speed and coordination are also needed (Andrea et al., 1993). However, it includes rapid, irregular and variable, short-term, high-intensity efforts in ski, cold and mountain environments (Turnbull et al., 2019). Skiing and wrestling training and competition environments are different. For example, wrestlers 
works in gym. Competitions are held in front of the spectators in gyms. On the skiing, on white snow training is carried out and there are spectators in the competition near the finish line.). Ski clothes and colors have an impact on the psychological state of children. White is used for purity, peace, goodness. It represents calm, relaxation and inner peace (Yamaner and Imamoglu, 2018; Imamoglu, 2010; Imamoglu 2011). In general, the stressful environment in wrestling is higher than the skiers. For this reason, the stress conditions of athletes investigating lipid profile should be investigated. Garry and McShane (2001) in a study, demonstrated that the strongest relationship between Body Mass Index and lipoprotein levels. This status occurred between Body Mass Index and the TC/HDL-C ratio. Players with the highest BMIs and elevated TC/HDL-C ratio may be those at greatest risk for cardio vascular disease, regardless of total cholesterol or LDL-C values. In wrestlers, skeletal muscles performing an intermittent physical exercise of unstable intensity, such as abrupt, explosive attacks, and counter attacks are particularly exposed to damage because of a disruption of sarcomeres leading to an intensified Creatine Kinase efflux into the extracellular space (Agnieszka et al., 2017). Wrestlers need to reduce their body weight and pay more attention to their diet.

\section{Conclusion}

Although the wrestlers' training levels were always found to be difference than the skiers, TG values were not found to be different. But the total cholesterol, HDL-C and LDL-C levels of skiers were found better than wrestlers. This result can show that middle and high level of regular different exercises did cause little differences in lipid and lipoprotein levels. Plasma lipid and lipoprotein values of the wrestler and skiers has showed could not be exposed to risk of cardiovascular diseases in the present status. Blood parameter values should be examined separately on Cross-country skiers and alpine skiers. In addition, wrestlers should pay more attention to their body weight and nutrition.

\section{References}

Aydogan, A. (2017). Comparison of Lipid and Lipoprotein Values of Different Wrestlers, European Journal of Physical Education and Sport Science, 3(12), 39-47.

Bedir, A., Adam, B., İmamoğlu, O. Et al. (1998). The Effect of Exercise Training on Lipid Profile in Turkish Young Adults. The New Journal of Medicine (Supplement 1), 15(1), 12-14.

Boden, W. E. (2000). High-density lipoprotein cholesterol as an independent risk factor in cardiovascular disease: assessing the data from Framingham to the Veterans Affairs High-Density Lipoprotein Intervention Trial. Am $J$ Cardiol, 86((12A)) 19L- 22L. https://doi.org/10.1016/S0002-9149(00)01464-8

Bosco, C., Cotelli, F., Bonomi, R., Mognoni, P., \& Roi, G. S. (1994). Seasonal fluctuations of selected physiological characteristics of elite alpine skiers. European journal of applied physiology and occupational physiology, 69(1), 71-4. https://doi.org/10.1007/BF00867930

Callan, S. D., Brunner, D. M., Devolve, K. L., Mulligan, S. E., Hesson, J., Wilber, R. L., \& Kerney, J. T. (2000). Physiological profiles of elite freestyle wrestlers. $J$ Strength Cond Res., 14, 162-169. https://doi.org/10.1519/00124278-200005000-00008

Çetinkaya, G., \& İmamoğlu, G. (2018). Investigation of The Effect of Plates-Aerobic Exercises on Body Composition and Body Image in Obesity Female, The Journal of International Social Research, 11(59), 1451-1456.

Chaabene, H., Negra, Y., Bouguezzi, R., Mkaouer, B., Franchini, E,. Julio, U., \& Hachana, Y. (2017). Physical and physiological profile of wrestler athletes: a short review. J Strength Cond Res., 31(5), 1411-1442. https://doi.org/10.1519/JSC.0000000000001738

Çicek, G., Imamoglu, O., Gullu, A., Celik, O., Ozcan, O., Gullu, E., \& Yamaner, F. (2017). The effect of exercises on left ventricular systolic and diastolic heart function in sedentary women: Step-aerobic vs core exercises. Journal of Exercise Science \& Fitness, 15(2), 70-75. https://doi.org/10.1016/j.jesf.2017.07.002

Dressendorfer, R. H., \& Gahagen, H. (1979). Serum lipid levels in male runners. Physician Sports Med. 4, 119-123. https://doi.org/10.1080/00913847.1979.11948424

Durstine, L., Grandjean, P. W., Davis, P. G., Ferguson, M. A., Alterson, N. L., \& DuBose, D. K. (2001). Blood Lipid and Lipoprotein Adaptations to Exercise, Sports Medicine, 31(15), 1033-1062. https://doi.org/10.2165/00007256-200131150-00002

Earnest, C. P., Artero, E. G., Sui, X., Lee, D. C., Church, T. S., \& Blair, S. N. (2013). Maximal estimated cardiorespiratory fitness, cardio metabolic risk factors, and metabolic syndrome in the aerobics center longitudinal study. Mayo Clin Proc, 88, 259-270. https://doi.org/10.1016/j.mayocp.2012.11.006

Edward, T., Howley, B., \& Franks, D. (1992). Health Fitness. USA

Eryılmaz, S. K., \& Polat, M. A. (2018). Comparison of Isocapnic Buffering Phase of Young Female Cross-Country and 
Alpine Skiers, National Journal of Sport Sciences, 2(1), 8-19

Fletcher, G., Blair, S., Blumenthal, C., et al. (1992).Benefits and Recommendations for Physical Activity Programs for All Americans: a statement for health professionals by the Committee on Exercise and Cardiac Rehabilitation of the Council on Clinical Cardiology, American Heart Association. Circulation. 82, $340-344$. https://doi.org/10.1161/01.CIR.86.1.340

Franceschini, G. (2001). Epidemiologic evidence for high-density lipoprotein cholesterol as a risk factor for coronary artery disease. Am J Cardiol, 88((12A)) 9N-13N. https://doi.org/10.1016/S0002-9149(01)02146-4

Fritz, K. (1987). Effects on Exercise on High Density Lipoproteins and Other Lipoproteins. Lipid Disorders. 5, $23-31$.

Garrison, R. J, Higgins, M. W., \& Kannel, W. B. (1996). Obesity and coronary heart disease. Curr Opin Lipidol. 7, 199202. https://doi.org/10.1097/00041433-199608000-00005

Garry J. P., \& McShane, J. J. (2001). Analysis of Lipoproteins and Body Mass Index in Professional Football Players, Preventive Cardiology, 103-105. https://doi.org/10.1111/j.1520-037X.2001.00534.x

Ginsburg, G. S., Agil, A., O’Toole, M., Rimm, E., Douglas, P. S., \& Rifai, N. (1996). Effects of a single bout of ultra-endurance exercise on lipid levels and susceptibility of lipids to peroxidation in triathletes. JAMA. 276, 221225. https://doi.org/10.1001/jama.1996.03540030055032

Gullu, E., Gullu, A., Cicek, G., Yamaner, F., Imamoglu, O., \& Gumusdag, H. (2013).The effects of aerobic exercises on cardiovascular risk factors of sedentary women. Int. J. Acad. Res, 5, 160-167. https://doi.org/10.7813/2075-4124.2013/5-3/A.23

Güneş S., Koca F., \& İmamoğlu O. (2019). The Effect Of 8 Weekly Alpine Discipline Basic Ski Training on Balance, Flexibility, Quickness And Durability in Children 8-10 Age Groups, Turkish Studies, 14(1), $381-393$. https://doi.org/10.7827/TurkishStudies.14866

Higuchi, M., Iwaoka, K., \& Fuchi, T., ve ark. (1989). Relation of Running Distance to Plasma HDL Cholesterol Levels in Middle-Aged Male Runners. Clin Physiol, 9(2), 121-130. https://doi.org/10.1111/j.1475-097X.1989.tb00963.x

Holmberg, H. C. (2015). The elite cross-country skier provides unique insights into human exercise physiology. Scandinavian Journal of Medicine \& Science in Sports, 25(4), 100-109. https://doi.org/10.1111/sms.12601

Hydren, J. R., Volek, J. S., Maresh, C. M., Comstock, B. A., \& Kraemer, W. J. (2013). Review of strength and conditioning for alpine ski racing. Strength \& Conditioning Journal, 35, 10-28. https://doi.org/10.1519/SSC.0b013e31828238be

İmamoğlu, G. (2010). The Effect of Colors on Sportive Performance, Mustafa Kemal University Physical Education and Sports Science, 1(2), 40-52.

İmamoğlu, G. (2011). The Effect of Colors on Sportive Performance in Football, Ataturk University Physical Education and Sports Science, 7(2), 1-5.

İmamoğlu, O., Akyol, P., \& Satıc1, A. (2017). The Effect of Aerobic Exercise and Weight-Lifting plus Aerobic Exercise on Blood Pressure and Blood Parameters in Sedentary Females, European Journal of Physical Education and Sport Science, 3(11), 194-206.

Imamoglu, O., Atan, T., Kishali, N. F., Burmaoglu, G., Akyol, P., \& Yıldırım, K. (2005). Comparison of lipid and lipoprotein values in men and women differing in training status. Biol of Sport, 22(3), 261-270.

Karnincic, H, Tocilj, Z, Uljevic, O, \& Erceg, M. (2009). Lactate profile during Greco-Roman wrestling matchx, J Sports Sci Med 8: 17-19

Koc, H. (2011). The comparison of blood lipid levels of athletes and sedentary college students. Pak J Med Sci, 27(3), 622-625.

Kraus, W., Houmard, J., Duscha, B. D., Knetzger, K. J., Wharton, M. B., McCartney, J. S., ... Slentz, C. A. (2002). Effects of the amount and intensity of exercise on plasma lipoproteins. $N$ Engl J Med, 347, 1483-1492. https://doi.org/10.1056/NEJMoa020194

Kujala, U. M., Kaprio, J., Taimela, S., \& Sarna, S. (1994). Prevalence of diabetes, hypertension, and ischemic heart disease in former elite athletes. Metabolism, 10, 1255-1260. https://doi.org/10.1016/0026-0495(94)90219-4

Labović, S. B., Donović, N., Andrejević, V., Banjari, I., Kurgaš, H., \& Zejnilović, M. (2015). Lipid Status of Professional Athletes, medical review, MD-Medical Data; 7(1), 021-025.

Leon, A. S., \& Sanchez, O. A. (2001). Response of blood lipids to exercise training alone or combined with dietary 
intervention. Med Sci Sports Exerc; 33, 502-515. https://doi.org/10.1097/00005768-200106001-00021

Lilić, L. J., Stefanović, R., Kocić, M., et al. (2009). Promene lipidnih parametara i antropometrijskih pokazatelja uhranjenosti u period intenzivnih priprema vrhunskih sportista, ActaMedica Medianae, 48(4), 5-9.

Lippi, G., Schena, F., Salvagno, G. L., Montagnana, M., Ballestrieri, F., \& Guidi, G. C. (2006). Comparison of the lipid profile and lipoprotein(a) between sedentary and highly trained subjects. Clin Chem Lab Med, 44(3), 322-326. https://doi.org/10.1515/CCLM.2006.056

Lohman, G. T., Roche, F. A., Martorell, R., editors. (1991). Anthropometric standardization reference manuel, Champaign, IL: Human Kinetics

Mann, S., Beedie, C., \& Jimenez, A. (2014). Differential effects of aerobic exercise, resistance training and combined exercise modalities on cholesterol and the lipid profile: review, synthesis and recommendations. Sports Med, 44, 211-221. https://doi.org/10.1007/s40279-013-0110-5

Manson, J. E., Stampfer, M. J., Hennekens, C. H., et al. (1987). Body weight and longevity. JAMA. 257, 353-358. https://doi.org/10.1001/jama.257.3.353

Pedersen, B. K., \& Saltin, B. (2006). Evidence for prescribing exercise as therapy in chronic disease. Scand J Med Sci Sports 16(Suppl 1), 3-63. https://doi.org/10.1111/j.1600-0838.2006.00520.x

Rosato, F. D. (1990). Fitness and Wellness the Physical Connection. U.S.A: Memphis State University

Ruppar, T. M., Conn, V. S., Chase, J. D., \& Phillips, L. J. (2014). Lipid outcomes from supervised exercise interventions in healthy adults. Am J Health Behav, 38, 823-830. https://doi.org/10.5993/AJHB.38.6.4

Sandbakk, Ø., \& Holmberg, H. C. A. (2014) Reappraisal of success factors for Olympic cross-country skiing. International journal of sports physiology and performance, 9(1), 117-121. https://doi.org/10.1123/ijspp.2013-0373

Sarzynski, M., Burton, J., Rankinen, T. Blair, S. N., Church, T. S. Després, J. P., \& Bouchard, C. (2015). The effects of exercise on the lipoprotein subclass profile: a meta-analysis of 10 interventions. Atherosclerosis, 243, 364-372. https://doi.org/10.1016/j.atherosclerosis.2015.10.018

Seiler, K. S., \& Kjerland, G. Ø. (2006). Quantifying training intensity distribution in elite endurance athletes: is there evidence for an "optimal" distribution? Scandinavian Journal of Medicine \& Science in Sports, 16(1), 49-56. https://doi.org/10.1111/j.1600-0838.2004.00418.x

Staib, J. L., Im, J., Caldwell, Z., \& Rundell, K. W. (2000). Cross-country ski racing performance predicted by aerobic and anaerobic double poling power. Journal of strength and conditioning research, 14(3), 282-288. https://doi.org/10.1519/00124278-200008000-00007

Stamler, J., Wentworth, D., \& Neaton, J. D. (1986). Is relationship between serum cholesterol and risk of premature death from coronary heart disease continuous and graded? Findings in 356,222 primary screenees of the Multiple Risk Factor Intervention Trial (MRFIT), JAMA, 28; 256(20), 2823-2828. https://doi.org/10.1001/jama.256.20.2823

Stevens, J., Cai, J., Pamuk E. R., Williamson, D. F., Thun, M. J., \& Wood, J. L. (1998). The effect of age on the association between body mass index and mortality. $N$ Engl $J$ Med. 338, 1-7. https://doi.org/10.1056/NEJM199801013380101

Tambalis, K., Panagiotakos, D. B., Kavouras, S. A., \& Sidossis, L. S. (2008). Responses of Blood Lipids to Aerobic, Resistance, and Combined Aerobic With Resistance Exercise Training: A Systematic Review of Current Evidence, Angiology, 60(5), 614-632. https://doi.org/10.1177/0003319708324927

Taylor, R. S., Brown, A., Ebrahim, S., Jolliffe, J., Noorani, H., Rees, K., ... Oldridge, N. (2004). Exercise-based rehabilitation for patients with coronary heart disease: systematic review and meta-analysis of randomized controlled trials. Am J Med. 116, 682-692. https://doi.org/10.1016/j.amjmed.2004.01.009

Thompson, P. D., Cullinane, E. M., Sady, S. P., et al. (1991). HDL-C metabolism in endurance athletes and sedentary men. Circulation, 84, 140-152. https://doi.org/10.1161/01.CIR.84.1.140

Tran, Z. V., Weltman, A., Glass, G. V., \& Mood, D. (1983). The effects of exercise on blood lipids and lipoproteins; a meta-analysis of studies. Med Sci Sports Exerc, 15, 393-402. https://doi.org/10.1249/00005768-198315050-00009

Tunstall-Pedoe, H., Woodward, M, Tavendale, R, Brook, R. A., \& McCluskey, M. K. (1997). Comparison of the prediction by 27 different factors of coronary heart disease and death in men and women of the Scottish heart health study: Cohort study. BMJ. 315:722-729. https://doi.org/10.1136/bmj.315.7110.722 
Turnbull, J., Kilding, A. E., \& Keogh, J. (2019). Physiology of Alpine Skiing: A review, https://www.researchgate.net/publication/24247534_Physiology_of_alpine_skiing:1-36,

Werner, W. K., Hoeger, S., \& Hoeger, A. (1990). Fitness and Wellness. USA: Colorado

White, A. T., \& Johnson, S. C. (1991). Physiological comparison of international, national and regional alpine skiers. International Journal of Sports Medicine, 12(4), 374-378. https://doi.org/10.1055/s-2007-1024697

White, A. T., \& Johnson, S. C. (1993). Physiological aspects and injury in elite alpine skiers, Sports Medicine, 15(3), 170-178. https://doi.org/10.2165/00007256-199315030-00003

Wood, P. (1996). Exercise and Lipids. The American Journal of Sports Medicine, 24(6), 59-60. https://doi.org/10.1177/036354659602406S17

World Health Organization (WHO). (2004). WHO global strategy on diet, physical activity and health. Food Nutr Bull 25(3), 292-302. https://doi.org/10.1177/156482650402500310

Yamaner, F., \& İmamoğlu, G. (2018). Sport performance colors power and effect. Turkish Studies, 13(15), 515-526. https://doi.org/10.7827/TurkishStudies.13602

Zembron-Lacny, A., Ziemann, E., Zurek, P., \& Hübner-Wozniak, E. (2017). Heat Shock Protein 27 Response To Wrestling Training in Relation to The Muscle Damage and Inflammation, Journal of Strength and Conditioning Research, 31(5), 1221-1228. https://doi.org/10.1519/JSC.0000000000001236

\section{Copyrights}

Copyright for this article is retained by the author(s), with first publication rights granted to the journal.

This is an open-access article distributed under the terms and conditions of the Creative Commons Attribution license which permits unrestricted use, distribution, and reproduction in any medium, provided the original work is properly cited. 